\title{
Physical signs of diffuse airways obstruction and lung distension
}

\author{
E. J . M . C A M P B E L L
}

From the Royal Postgraduate Medical School, and Hammersmith Hospital, London, W.1

\begin{abstract}
The following are physical signs which can be elicited in patients with chronic airways obstruction: a reduction in the length of the trachea palpable above the sternal notch ; tracheal descent with inspiration; excessive use of the scalene and sternomastoid muscles; excavation of the suprasternal and supraclavicular fossae during inspiration; jugular venous filling during expiration; loss of bucket-handle movement of the upper ribs; paradoxical movement of the lower ribs; and prolonged forced expiratory time.
\end{abstract}

Patients with chronic bronchitis and emphysema often have barrel-shaped chests which move en bloc, with considerable use of the accessory muscles of breathing. This description is rather general and it is probably more useful to describe the condition of the chest in terms of morediscrete abnormalities. I am not concerned here with the well-known signs such as increased anteroposterior diameter diminution of breath sounds or reduction in heart and liver dullness. The signs described below are less well-known and their possible physiological basis will be discussed.

These signs are best elicited with the patient lying propped up at about $45^{\circ}$ breathing quietly. If a sign is indefinite the patient can be asked to breathe more deeply.

\section{LENGTH OF TRACHEA PALPABLE ABOVE STERNAL NOTCH}

This can be recorded in fingerbreadths above the cricoid notch at the end of expiration. This distance varies from three to four fingerbreadths in young normal subjects to none in patients with severe chronic airways obstruction. The reduction is probably due to an elevation of the sternum relative to the hilum. Apart from its diagnostic use it is worth noting because it has a bearing on the performance and care of tracheostomy.

\section{TRACHEAL DESCENT WITH INSPIRATION}

This sign is not to be confused with the better known tracheal tug with systole due to an aortic aneurysm.

It is best felt by resting the tip of the index finger on the thyroid cartilage. This sign is some- times said to be present in any patient with respiratory distress, and anaesthetists associate it with deep anaesthesia or $\mathrm{CO}_{2}$ retention. However, I think the sign is more typical of chronic airways obstruction and is probably produced by the downward pull of the depressed diaphragm (Campbell, 1958).

\section{USE OF ACCESSORY MUSCLES}

Although many muscles may contract during respiratory distress the two important groups are the scalene and sternomastoids. In patients with chronic airways obstruction the skin clings to the prominences of the sternomastoid and the floor of the posterior triangle. This appearance may signify that these muscles are used more readily than usual during exercise but does not imply that they are continuously in action. This activity should be judged by palpation. The scalene muscles which can be felt by pressing the finger tips into the floor of the posterior triangle of the neck can be shown by electromyography to contract during inspiration in many normal subjects (Campbell, 1955 ; Raper, Thompson, Shapiro, and Patterson., 1966). However, palpable hardening of the muscle signifies either a stiff or chronically over-inflated chest. The sternomastoids are best examined by drawing them gently backwards with the thumb and first finger to feel if they become taut with inspiration. The sternomastoids may contract in great respiratory distress from any cause but their action is particularly associated with chronic over-inflation of the chest (Campbell and Friend, 1955). 
EXCAVATION OF SUPRASTERNAL AND SUPRACLAVICULAR FOSSAE DURING INSPIRATION

The folds and fossae around the root of the neck are prominent in many patients with chronic chest disease. In addition there may be an inspiratory recession. If this is distinguished from the contraction of the scalene and inspiratory elevation of the clavicles I think it probably implies that the intrathoracic pressure falls excessively during inspiration.

\section{JUGULAR VENOUS FILLING DURING EXPIRATION}

This sign indicates that the intrathoracic pressure is rising excessively due to airway obstruction.

\section{LOSS OF BUCKET-HANDLE MOVEMENT OF} UPPER RIBS

In patients with chronic airways obstruction causing overinflation and elevation of the sternum, there is a loss of the bucket-handle movement about the vertebro-sternal axis with retention or even exaggeration of the pump-handle movement about the axis of the neck of the rib. This can be detected clinically by spreading the first and second fingers of each hand and locking them on to the top of the second or third rib anteriorly, placing the second finger as far laterally as the rib can be felt before it disappears under the shoulder muscles. Normally the second (outer) finger swings outwards and upwards around the first finger during inspiration and the first finger does not move much. In patients with chronic airway obstruction the outer finger loses its movement relative to the inner; in extreme cases the inner finger moves upwards more than the outer.

\section{PARADOXICAL MOVEMENT OF COSTAL MARGIN} (HOOVER'S SIGN) (Hoover, 1920)

Normally the costal margin moves very little during quiet breathing but, if it does, it moves outwards and upwards. In some normal subjects it may move slightly inwards at the end of a maximum inspiration, but in chronic airway obstruction there is a greater tendency for it to move paradoxically. This is best appreciated by resting the first and second fingers on the costal margin near the anterior axillary line. When the sign is present in gross degree the margin is felt to move inwards throughout inspiration; when less gross the margin may move in a biphasic manner: initially it goes out, then in, and springs out again at the onset of expiration.
This sign is probably due to the inward traction of the depressed diaphragm. The normal diaphragm lifts the costal margin outwards (Camp 흐 bell, 1958).

\section{FORCED EXPIRATORY TIME}

This is the best and most direct sign of airways obstruction, the others being indirect in that theye arise from the inflation produced by airway ob $\vec{x}$ struction rather than the airway obstruction itself The sign is elicited by having the subject exhale. with his mouth wide open after a full inspiration:The exhalation should be continued until airflow ceases or the subject is forced to breathe in. The cessation of airflow can be judged by listening either at the mouth or, by stethoscope, over the trachea. The normal duration is less than foun seconds. Since the description by Lal, Ferguson. and Campbell (1964), Leith and Mead (1967) haveू shown that airflow persists for very long periods 0 during forced expiration in some older normap subjects. The rates (about $50 \mathrm{ml}$./ sec.) are, hows ever, too low to be detected clinically.

\section{DISCUSSION}

This list of signs is neither original nor exhaustive? I have chosen those which I believe are neglectedP. and which give particular insight into the disturbed mechanics of breathing. These signs arise from? three different but related disturbances. First, air ways obstruction: most directly related to this are the prolonged forced expiratory time and venous filling during expiration. Secondly, excessive pressure swings in the chest: these cause the supraclavicular excavation during inspiration and venous filling during expiration. Thirdly, increased lung volume: this I think causes all the other. signs, but the relationship is not simple becausen most of them are not present in a young subject breathing at a large lung volume whereas they are often seen in older subjects with long-standings disease, but in whom the resting lung volume is only moderately increased. I suspect that they reflect a mixture of age and the duration of chronic overinflation which cause the rib cage and? diaphragm to change their shape.

We have studied observer error in the elicitation of these signs (Godfrey, Edwards, Campbell Armitage, and Oppenheimer, 1969) and we arg also trying to define their clinical and physiog logical significance more exactly. I must, however 
emphasize that, necessary though they are, such studies cannot do full justice to these signs, first because externally imposed criteria-even if agreed-of 'presence or absence' do not reveal their value to those who regularly inspect the chest carefully. Secondly, the signs arise in the action of the respiratory muscles and the disturbed chest wall mechanics, which are not really measured by conventional physiological measurements of lung volumes and ventilatory capacity. Furthermore, the disability of the patient may be due partly to sensations generated by the abnormal muscular action and distorted mechanics of the diaphragm and rib cage.

I apologize for the frequent reference to my own interpretation, but there has as yet been little work in this field of respiratory mechanics.
I am grateful to Dr. C. M. Fletcher, Dr. S. Godfrey, and Dr. A. John Robertson for their advice.

\section{REFERENCES}

Campbell, E. J. M. (1955). The role of the scalene and sternomastoid muscles in breathing in normal subjects. An electromyographic study. J. Anat. (Lond.), 89, 378.

- (1958). The Respiratory Muscles and the Mechanics of Breathing. Lloyd-Luke, London.

- and Friend, J. (1955). Action of breathing exercises in pulmonary emphysema. Lancet, $1,325$.

Godfrey, S., Edwards, R. H. T., Campbell, E. J. M., Armitage, P. and Oppenheimer, E. A. (1969). The repeatability of physical signs in airways obstruction. Thorax, 24, 4.

Hoover, C. F. (1920). Definitive percussion and inspection in estimating size and contour of heart. J. Amer. med. Ass., 75, 1626.

Lal, S., Ferguson, A. D., and Campbell, E. J. M. (1964). Forced expiratory time: a simple test for airways obstruction. Brit. med. J., 1,814 .

Leith, D. E., and Mead, J. (1967). Mechanisms determining residual volume of the lungs in normal subjects. J. appl. Physiol., 23, 221.

Raper, A. J., Thompson, W. T., Shapiro, W., and Patterson, J. L. (1966). Scalene and sternomastoid muscle function. Ibid., 21, 497. 